\title{
ANÁLISIS DEL DATIVO EN CONSTRUCCIONES IMPERSONALES: LOS CONCEPTOS DE SUJETO Y DE SEMISUJETO EN GRIEGO ANTIGUO*
}

\author{
Luz ConTI \\ Universidad Autónoma de Madrid \\ luz.conti@uam.es
}

\section{ANALYSIS OF THE DATIVE IN IMPERSONAL CONSTRUCTIONS: THE CONCEPTS OF SUBJECT AND SEMI-SUBJECT IN ANCIENT GREEK}

Las construcciones impersonales con un complemento en dativo y otro en genitivo se documentan en griego en un número muy reducido de verbos que designan interés o necesidad. Aunque se trata de una construcción presente también en otras lenguas indoeuropeas antiguas, en griego se documenta a partir de fecha posthomérica. Las construcciones personales, más recientes en otras lenguas, se documentan en griego, sin embargo, ya desde Homero. El dativo de la construcción impersonal designa entidades humanas y, además, expresa el Experimentador y el tópico. Estas propiedades designativas, semánticas y pragmáticas, próximas a las del sujeto prototípico, permiten al dativo ciertos comportamientos sintácticos característicos del sujeto. Nos hallamos, pues, ante un semisujeto, es decir, ante un complemento verbal que, a pesar de su codificación gramatical, diferente de la del sujeto, presenta unas propiedades y unos comportamientos sintácticos próximos a los de este. El genitivo de la construcción impersonal objeto de estudio presenta también compor-
Impersonal constructions holding a complement both in dative and genitive are attested in Greek with a few verbs, which share the property of expressing the interests or the needs of human beings. These constructions, which occur in several ancient IndoEuropean languages, are documented in the postHomeric period in the case of Greek. In the opposite, personal constructions, which appear more recently in other languages, are already documented in Greek since Homer's times. The dative in the impersonal construction refers to human entities, codes the Experiencer and it is also the topic. These properties, which are close to those of the prototypical subject, seem to allow the dative to show some subject-like syntactic behaviour. In fact, we will argue that the dative in the impersonal construction behaves as a semi-subject, i. e. a verbal complement which, regardless of its coding, does have a set of properties that are typically associated with the subject in Greek. As well as the complement in dative, the complement in genitive in the impersonal construction exhibits a syntactic behaviour similar to

* Este artículo ha resultado del trabajo llevado a cabo en varias estancias de investigación en las Universidades de Wurzburgo y de Colonia en el marco de una beca Humboldt ( 1 de agosto de 2007-31 de enero de 2008 y 1 de julio de 2008-31 de agosto de 2008). Una parte del material se analizó en el marco del Proyecto de Investigación HUM 2006-13297/FILO. Agradezco a C. Conti, E. Crespo, J. L. García Ramón, H. Hettrich, M. D. Jiménez, S. Luraghi y S. Ziegler su ayuda y sus observaciones. 
tamientos sintácticos característicos del sujeto, si bien estos comportamientos solo coinciden parcialmente con los del dativo.

Palabras clave: sujeto; semisujeto; construcciones impersonales; dativo; genitivo. the subject. However, the genitive does not follow the same patterns the dative does in the impersonal construction.

Keywords: subject; semi-subject; impersonal constructions; dative; genitive.

\section{INTRODUCCIÓN}

En griego antiguo, al igual que en las restantes lenguas indoeuropeas con marcadores de caso, el sujeto de predicados verbales personales se codifica en nominativo. Junto a esta propiedad formal, el sujeto prototípico presenta también propiedades semánticas, pragmáticas y sintácticas que reflejan el vínculo estrecho y particular que establece con el predicado. En lo que atañe a su contenido semántico, la asignación del sujeto en la oración sigue unas pautas bien determinadas; con un principio antropocéntrico como razón última, el sujeto de la oración se asigna preferentemente a seres humanos, o al menos animados, cuya implicación en la acción verbal es importante y, sobre todo, activa ${ }^{1}$ : esto explica la frecuencia con la que el sujeto designa el Agente o el Experimentador en la oración ${ }^{2}$. Las características pragmáticas del sujeto se definen por su interés informativo; la función pragmática de tópico, propia del sujeto prototípico, responde, por lo general, a una cuestión fácil de formular: de los participantes implicados en la situación que se pretende describir, ¿sobre cuál puede versar la información? La fácil identificación de su referente es uno de los rasgos más importantes del tópico; el hablante transmite información sobre un elemento que considera conocido, bien porque ya ha sido mencionado en el discurso, bien porque el oyente puede suponer su identidad a partir de su propio conocimiento de la realidad ${ }^{3}$. En general, el tópico encabeza la oración ${ }^{4}$.

${ }^{1}$ Esta tendencia, de carácter general entre las lenguas que poseen la relación gramatical de sujeto, ha sido descrita, entre otros, por Fillmore 1968, Keenan 1976, Keenan y Comrie 1977 y por Itagaki y Prideaux 1985.

${ }^{2}$ Entiendo por Agente la entidad humana que controla de forma consciente el estado de cosas descrito en la oración y por Experimentador la entidad humana que percibe, siente, juzga o comprende una situación (Crespo, Conti y Maquieira 2003, pp. 106-108); el grado de control del Experimentador sobre el estado de cosas descrito en la oración es menor que el del Agente.

3 Para una definición de la función de tópico y de sus características, véanse, entre otros, Chafe 1976, Li y Thompson 1976 y Dik 1978.

${ }^{4}$ Como ya apuntara Demetrio en su tratado Sobre la Elocuencia, «Lo primero que se menciona es aquello sobre lo que se trata» (Eloc. 199). Sobre la tendencia del sujeto, designación 
Más difícil resulta la precisión de las propiedades sintácticas del sujeto. En principio, la concordancia en número y persona con el predicado verbal parece ser un rasgo característico del sujeto en el ámbito indoeuropeo, si bien la importancia de este fenómeno morfosintáctico ha sido puesta en entredicho recientemente en el caso de algunas lenguas germánicas modernas. 5 . Otros rasgos, como la determinación del número y de la persona de los pronombres reflexivos, son propios del sujeto, pero no siempre exclusivos de él (cf. § II 1). En el análisis sintáctico del sujeto en las lenguas indoeuropeas, el trabajo de Cole, Harbert, Hermon y Sridhar 1980 sigue siendo aún hoy punto de referencia. En este artículo, sus autores intentan, mediante un estudio comparativo sincrónico y diacrónico entre lenguas de diferente filiación genética ${ }^{6}$, determinar las propiedades sintácticas del sujeto en las lenguas naturales y describir los procesos de adquisición de estas propiedades por parte de los complementos del predicado.

Al margen de sus propiedades semánticas, pragmáticas y sintácticas, la tradición gramatical del griego considera sujeto a aquel complemento del predicado verbal expresado mediante el nominativo. Puesto que en las lenguas con un sistema de relaciones gramaticales las propiedades semánticas, pragmáticas y sintácticas de un elemento condicionan su codificación morfológica, y no a la inversa, esta definición del sujeto es, posiblemente, la más precisa ${ }^{7}$. En consecuencia, todo complemento de un predicado verbal personal que presente algunas características del sujeto, pero no su codificación gramatical en nominativo, no es, en rigor, un sujeto, sino un semisujeto ${ }^{8}$.

habitual del tópico, a encabezar la oración en griego, véanse Frisk 1932, Dover 1960, Crespo 1983 y, más recientemente, H. Dik 1995 y 2007.

${ }^{5}$ Cf. Eythórsson y Barðdal 2005, p. 860 ss. En griego antiguo, sin embargo, los ejemplos en los que el nominativo no concierta con el predicado en número y persona son escasísimos

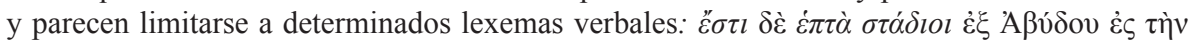
$\dot{\alpha} \pi \alpha v \tau i ́ o v$ (Hdt. VII 34.4). El tema merece un estudio minucioso que no puede abordarse aquí.

${ }^{6}$ Se trata del germánico, el polinesio y el georgiano.

${ }^{7}$ Por lo general, los cambios de las propiedades semánticas, pragmáticas y sintácticas de un elemento desembocan en un cambio de su codificación gramatical; el cambio en la codificación gramatical es el paso último de una evolución en cuyas fases intermedias un elemento puede presentar propiedades típicas de una categoría gramatical determinada, pero no su forma. Una exposición sugerente de este proceso en las lenguas indoeuropeas es la que ofrece Sasse 1982, p. 279 ss., en su trabajo sobre la consolidación de la categoría del sujeto en el ámbito indoeuropeo.

${ }^{8}$ Sasse 1982. Sobre el fenómeno de los semisujetos en lenguas de diferente filiación véase el volumen editado por Bhaskararao y Karumuri Venkata 2004. 
En griego antiguo son varias las formas que admiten un análisis como semisujeto. Así, tanto los sintagmas preposicionales que expresan una cantidad aproximada como el genitivo partitivo de construcciones personales presentan en ocasiones concordancia en número y persona con el predicado verbal ${ }^{9}$. Como indican los siguientes ejemplos, los adjetivos y los participios empleados en función predicativa se codifican en nominativo, y no en la forma correspondiente del semisujeto:

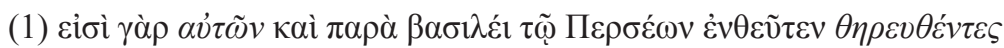
(Hdt. III 102.10).

Pues incluso en el palacio del rey de los persas hay algunas (sc. hormigas del desierto) que han sido atrapadas allí.

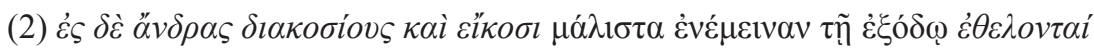
(Th. III 20.2).

Unos doscientos veinte hombres se mantuvieron dispuestos a salir.

El genitivo empleado en las construcciones impersonales de algunos verbos de sentimiento y de necesidad presenta también un comportamiento como semisujeto, ya que, además de caracterizarse por algunas propiedades semánticas, pragmáticas y sintácticas presentes en el sujeto ${ }^{10}$, admite la aposición y la coordinación con estructuras completivas a las que la theoria recepta atribuye esta función ${ }^{11}$ :

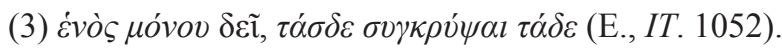

Una sola cosa es necesaria: que estas oculten eso.

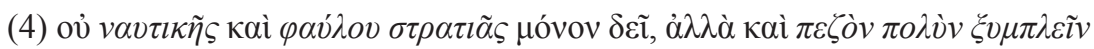
(Th. VI 21.1).

No solo hay necesidad de una flota y de un simple ejército, sino también de que naveguen con ellos muchas tropas de a pie.

${ }^{9}$ Sobre el genitivo semisujeto en construcciones personales, cf. Conti 2008 [2010].

${ }^{10}$ Conti 2009 [2010], pp. 186 ss.

${ }^{11}$ Cf. Kühner y Gerth 1904, pp. 33-35, y Schwyzer y Debrunner $1988^{5}$, p. 377 s. Sobre el uso de $̋ \sigma \tau \varepsilon+$ inf. en dependencia de construcciones impersonales véase García Ramón 1999, pp. 176-179. 
Con frecuencia, las construcciones impersonales de verbos de sentimiento y de necesidad presentan junto al genitivo un complemento en dativo con referente humano que expresa el Experimentador ${ }^{12}$. El genitivo, por su parte, admite un análisis como expresión del Paciente, como expresión de la Causa y también como expresión de la Referencia ${ }^{13}$ :

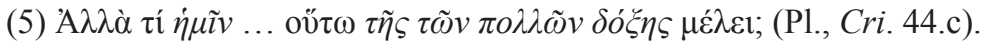

Pero, ¿por qué nos interesamos tanto por la opinión de la mayoría?

Puesto que, como acabamos de ver, la designación de referentes humanos y la expresión del Experimentador son características propias del sujeto prototípico, cabe preguntarse si, junto a estos rasgos de orden designativo y semántico, el complemento en dativo presenta también rasgos de orden pragmático o sintáctico cercanos a los del sujeto. De ser así, se habrá de precisar si estos rasgos coinciden o no con los del complemento en genitivo de estas mismas construcciones impersonales, que han sido analizados en un trabajo previo $^{14}$. En el caso de falta de coincidencia entre los rasgos del dativo y del genitivo, se habrá de determinar cuál de los dos complementos presenta una mayor proximidad al sujeto prototípico de construcciones personales y qué factores condicionan este hecho.

\section{PResentación Y ANÁLISIS DE LOS DATOS}

El presente trabajo analiza las construcciones impersonales con un complemento en genitivo y otro en dativo. La búsqueda de datos, llevada a cabo con la ayuda del CD-Rom TLG E (Thesaurus Linguae Graecae versión E), se

${ }^{12}$ Frente al dativo, que designa, salvo contadas excepciones, referentes humanos individuales o colectivos, el genitivo designa tanto referentes inanimados como referentes animados.

${ }^{13}$ En mi opinión, la interpretación del genitivo está estrechamente vinculada con el mayor o menor grado de control que se presuponga en el Experimentador. En principio, la atribución de un grado de control alto al Experimentador favorece un análisis del genitivo como expresión del Paciente; por el contrario, la atribución de un grado de control más bajo favorece un análisis del genitivo como expresión de la Causa. La posibilidad de interpretar el genitivo de estas construcciones como expresión de la Referencia se ve apoyada por la alternancia que se observa

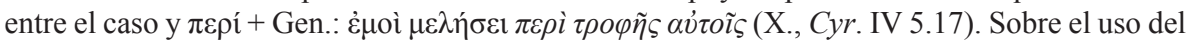
genitivo griego en la expresión de estas funciones, cf., entre otros, Crespo, Conti y Maquieira 2003, p. 132 ss.

${ }^{14}$ Conti 2009 [2010]. 
ha centrado en las obras de Homero, Esquilo, Heródoto, Sófocles, Eurípides, Tucídides, Aristófanes, Platón, Jenofonte, Demóstenes y Plutarco. Con esta selección de autores se pretendía operar con un material de amplia perspectiva cronológica que combinara obras en prosa y en verso. Puesto que en las lenguas naturales el empleo de construcciones impersonales con una codificación del Experimentador en una forma distinta de la del sujeto es un fenómeno frecuente, tanto en los verbos de sentimiento y de necesidad como en los de sensación y en los de percepción — ya sea sensorial o intelectual— ${ }^{15}$, se consideró oportuno analizar y clasificar las construcciones sintácticas de un número representativo de verbos pertenecientes a estos grupos ${ }^{16}$. A pesar de la gran cantidad de datos recogidos, las estructuras objeto de estudio se observan tan solo en cua-

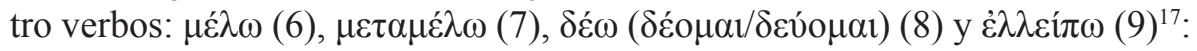

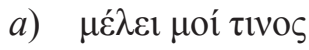

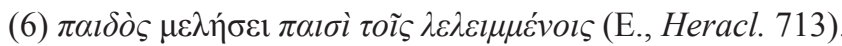

${ }^{15}$ Cf. Moreno 1990a y 1990b, Bossong 1998, Haspelmath 2001 y Wegener 2001. Para las lenguas indoeuropeas antiguas véase Miklosich 1883. El alemán, al igual que otras lenguas germánicas, presenta aún hoy algunas construcciones de este tipo; en la mayor parte de los casos estamos ante construcciones que van cediendo irremisiblemente frente a construcciones personales: Mir liegt an etwas «tengo interés en algo», Mir mangelt an etwas «me falta algo», Mich friert «tengo frío», Mir dünkt «me parece». Sobre las construcciones antiguas del tipo Es jammert mich des Volks «me da pena el pueblo», con acusativo y genitivo, y del tipo Dem Räuber jammerte des armen Teufels «Al ladrón le dio pena el pobre diablo», con dativo y genitivo, véase, entre otros, Hermann 1926, pp. 46-47. En español, expresiones del tipo Así me pese de mis culpas (Bello 1847, p. 501) han caído en desuso.

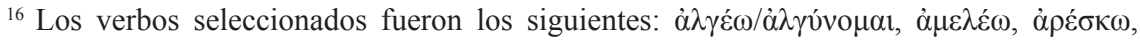

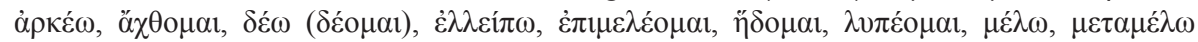

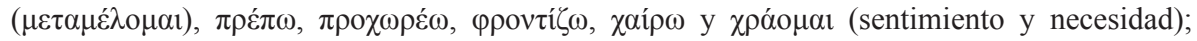

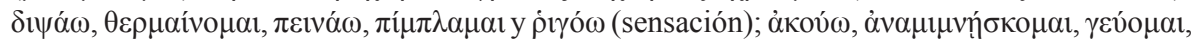

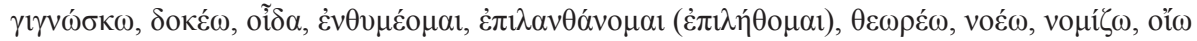

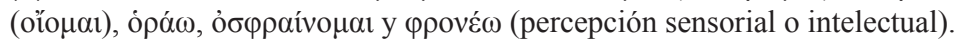

${ }_{17}$ Naturalmente, las construcciones impersonales con un Experimentador codificado en dativo son relativamente frecuentes en griego en la expresión de sentimientos y de percepciones

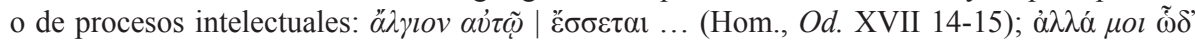

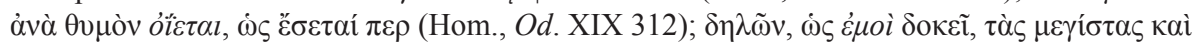
$\dot{\varepsilon} \lambda \alpha \chi i ́ \sigma \tau \alpha \varsigma$ (Th. I 10.4). Menos común es el uso de este tipo de construcciones en la expresión de

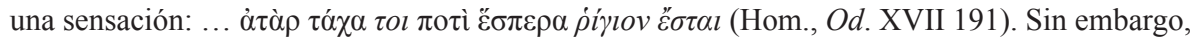
todas las construcciones sin un complemento en genitivo se han dejado fuera de consideración; serán analizadas en trabajos posteriores. 
De tu hijo se ocuparán los hijos restantes.

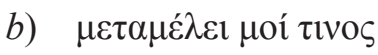

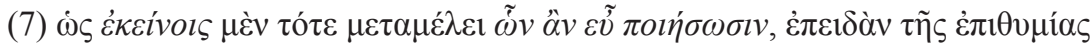
$\pi \alpha v ́ \sigma \omega v \tau \alpha 1$ (Pl., Phdr. 231a).

Pues aquellos (sc. los enamorados) se arrepienten de sus buenas acciones una vez que cesan en su deseo.

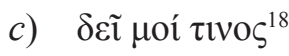

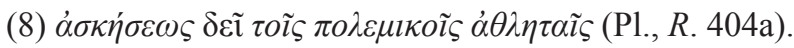

Ejercicio es lo que necesitan los atletas guerreros.

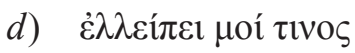

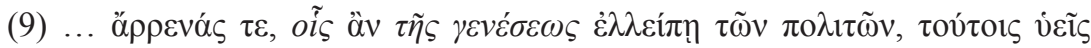

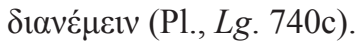

... Y que a los varones se los distribuya como hijos entre aquellos ciudadanos a los que falte descendencia.

Junto a las construcciones impersonales con genitivo y dativo, muy poco frecuentes, estos verbos presentan un uso con una estructura completiva en función de sujeto, como en (10), y construcciones personales cuyo sujeto en

${ }^{18}$ Con $\delta \varepsilon \tilde{i}$ el participante humano no solo se designa en dativo, sino también en acusativo

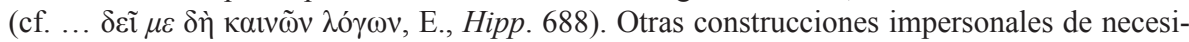
dad, como la de la forma $\chi \rho \eta ́$ y sus variantes, solo presentan de forma excepcional el dativo; el acusativo es en estos casos la designación habitual del participante humano, como muestra el

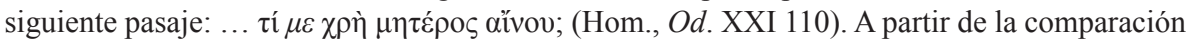
con otras lenguas indoeuropeas, Hermann 1926, pp. 284-287 y 291, supuso que el acusativo fue la codificación originaria del participante humano en las construcciones impersonales en las que se expresaba un sentimiento o un estado de necesidad. Sin embargo, los datos no son, en mi opinión, concluyentes, por lo que es también posible suponer que, al menos con determinados verbos, el uso del dativo es también antiguo. El empleo del acusativo se correspondería, en principio, con la atribución de un grado de control nulo o muy reducido al participante humano, mientras que el dativo sería esperable en aquellos casos en los que el grado de control del participante humano sobre el estado de cosas fuera más alto. 
nominativo se corresponde, bien con el Experimentador en dativo de la construcción impersonal (11), bien con el genitivo ${ }^{19}(12)$ :

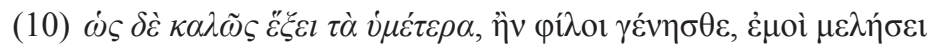
(X., Cyr. III 2.13).

De que vuestros asuntos vayan bien me ocuparé yo, si es que llegáis a ser amigos nuestros.

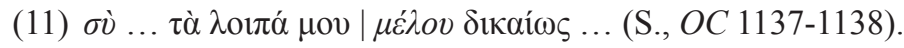

En adelante tú sigue ocupándote de mí debidamente.

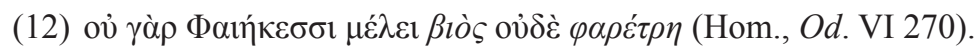

Pues a los feacios no les interesan ni el arco ni la aljaba.

De hecho, son estas las construcciones empleadas ya desde Homero. Las estructuras impersonales con genitivo y con dativo, por el contrario, no se documentan en la epopeya, y apenas ofrecen ejemplos en Heródoto ${ }^{20}$; en los autores posteriores, sobre todo los trágicos, su uso es más frecuente, aunque sigue siendo un hecho muy marginal.

Dado que los verbos que expresan sentimientos y sensaciones presentan en varias lenguas indoeuropeas la construcción impersonal que aquí se analiza, hemos de suponer que nos hallamos ante un fenómeno heredado ${ }^{21}$; el alcance de este fenómeno en indoeuropeo está aún, sin embargo, por determinar, ya que la falta de coincidencia entre los datos de las lenguas derivadas exige un

${ }^{19}$ Como se observa en los ejemplos (11) y (12), el segundo complemento del predicado de la construcción personal se codifica en genitivo en el primer tipo de oraciones y en dativo en el segundo. La asociación frecuente del uso de la voz media con la codificación en nominativo del Experimentador en estos contextos es un aspecto interesante que merecería un estudio detallado.

${ }^{20}$ Siempre se ha llamado la atención sobre el escasísimo uso de construcciones impersonales en los primeros estadios del griego y del antiguo indio, construcciones ausentes, incluso, en el caso de los verbos que designan fenómenos meteorológicos (cf., entre otros, Hermann 1926 y, recientemente, Cuzzolin 2007 y Cuzzolin y Napoli 2009). Si en el ámbito indoeuropeo las construcciones impersonales son, como fenómeno sintáctico, más antiguas que las personales (cf. Meillet 19378 , p. 358; Krahe 1972, p. 59; Hartmann 1977, p. 161, y Sasse 1982, p. 279 ss.), el comportamiento del griego y del antiguo indio, lenguas muy conservadoras, resulta difícil de explicar (para los datos del védico véanse, entre otros, Delbrück $1968^{2}$, p. 4 s., y Hettrich 2007, CbII 26-28, 117-122, 131 s., 149-151 y 249 s.). Esta cuestión sigue aún abierta (cf. Conti 2009 [2010], pp. 201-204).

${ }^{21}$ Cf., entre otros, Wackernagel 1920, p. 117, y Brugmann 1925, p. 24 ss. 
estudio comparativo minucioso ${ }^{22}$. En el presente trabajo, limitado al análisis del griego, no se abordarán estas cuestiones.

\section{Propiedades pragmáticas y sintácticas del dativo}

En el análisis de las propiedades pragmáticas del dativo se han tenido en cuenta tres factores: sus características designativas, su valor informativo y su posición en la oración ${ }^{23}$. Las características designativas del dativo se corresponden, sin duda alguna, con las del tópico: el dativo designa, como ya se ha señalado, seres humanos; con frecuencia, el referente de estos seres humanos es único y remite a la primera o a la segunda persona ${ }^{24}$. Se trata, en consecuencia, de entidades de fácil identificación que se sitúan en los puestos más altos de la escala de animación.

El estudio del valor informativo del caso y de su posición en la oración plantea más dificultades y da lugar, por tanto, a un cierto margen de error. Aun así, el análisis de los ejemplos y de su contexto permite concluir que la expresión regular del tópico con estos verbos es el sintagma en dativo, y no el sintagma en genitivo.

Con los verbos de interés este hecho está en consonancia con el orden de palabras, ya que, tal y como cabe esperar de un elemento topical, el sintagma en dativo encabeza la oración en más de la mitad de los ejemplos ${ }^{25}$. El empleo del sintagma en genitivo en esta posición responde en la mayor parte de los casos, por el contrario, a un uso como expresión del foco (13); solo

${ }^{22}$ En el grupo germánico, por ejemplo, el espectro de verbos que presentan esta construcción es más amplio que en lenguas como el griego o el latín (cf. Barðdal 2006).

${ }^{23}$ La compleja cuestión del orden de palabras en griego antiguo ha sido estudiada recientemente por H. Dik 1995 y 2007. La autora distingue, siguiendo a Dik, cuatro funciones: tópico y foco, expresadas por elementos que se integran en la cláusula, y tema y apéndice, expresadas por elementos que no se integran en ella (para una explicación de estos términos véase H. Dik 2007, p. 31 ss.). En griego, la posición inicial en la cláusula propiamente dicha es característica tanto del tópico como del foco. La distinción de funciones pragmáticas no siempre es fácil, sobre todo en una lengua de corpus como el griego antiguo, por lo que el análisis de los datos que se ofrece en el presente trabajo se habrá de entender como una mera aproximación a este problema en las estructuras objeto de estudio.

${ }^{24}$ La designación de entidades humanas en singular referidas a la primera o segunda persona es propia del tópico prototípico (cf., entre otros, Dik 1997, p. 357 ss.).

${ }^{25}$ En concreto, en 51 de un total de 90 . El orden de palabras más frecuente es dativogenitivo-verbo $(25 \times)$, seguido de cerca por dativo-verbo-genitivo $(21 \times)$. 
de forma ocasional el genitivo que se sitúa en posición inicial de oración expresa el tópico $(14)^{26}$ :

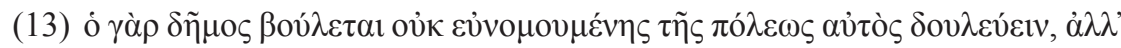

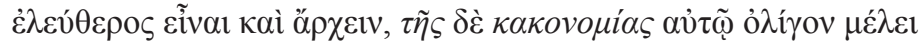
(X., Ath. 1.8).

Pues el pueblo no quiere ser esclavo, aunque la ciudad esté bien gobernada, sino ser libre y tener el mando; el mal gobierno a él le importa poco.

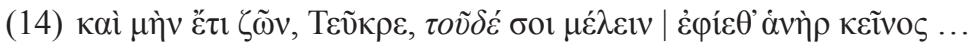
(S., Aj. 990-991) ${ }^{27}$.

$\mathrm{Y}$ en verdad, Teucro, que el deseo de aquel hombre, mientras estuvo vivo, fue que tú te ocuparas de él (sc. su hijo).

Con los verbos de necesidad el orden de palabras se ajusta menos a lo esperado: aunque el sintagma en dativo parece ser también la expresión habitual del tópico, su aparición al comienzo de la oración se limita a 17 ejemplos de un total de 67; en el resto, la posición inicial es ocupada por el sintagma en genitivo o por el verbo ${ }^{28}$. El uso como foco permite explicar en la mayor parte de las ocasiones la posición inicial tanto del uno como del otro:

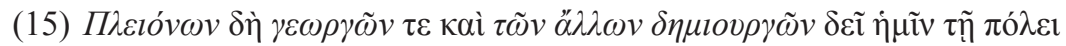
(P1., R. 371a).

Sin duda que más labradores y artesanos es lo que necesita nuestra ciudad

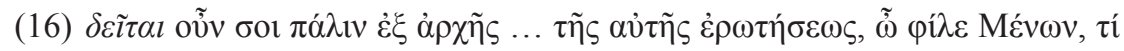

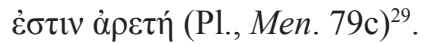

${ }^{26}$ El genitivo se sitúa al comienzo de la oración en 31 ejemplos. Entre ellos se encuentran también algunos en los que la posición inicial del caso responde a un funcionamiento como

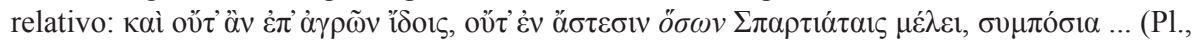
Lg. 637a).

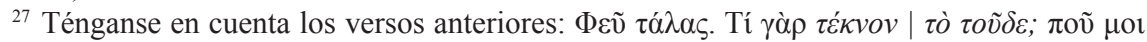

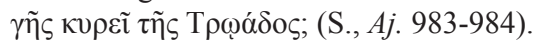

${ }^{28}$ El genitivo se sitúa en posición inicial en 19 ejemplos y el verbo en 21. La frecuente aparición del verbo en posición inicial es llamativa, sobre todo si tenemos en cuenta que los verbos de interés solo ofrecen 18 ejemplos de un total de 90 .

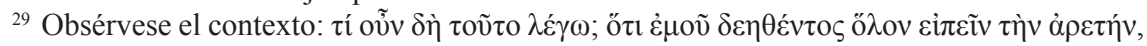

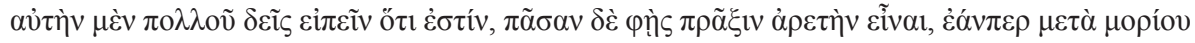


Es preciso, pues, que te vuelvas a plantear la misma pregunta desde el comienzo, mi querido Menón: ¿Qué es la virtud?

El análisis sintáctico del dativo ha partido del artículo de enfoque tipológico de Cole, Harbert, Hermon y Sridhar (1980), que definen los comportamientos propios del sujeto frente a los demás complementos del predicado. Estos comportamientos, exclusivos en principio del sujeto, pueden ser adquiridos también por otros complementos ${ }^{30}$.

Los comportamientos que caracterizan al sujeto en diferentes lenguas y que, de darse en otro elemento, demuestran su aproximación sintáctica a esta categoría y, por consiguiente, su carácter de semisujeto, son, según Cole y sus colegas, los siguientes:

— Posibilidad de ser elidido y de facilitar la elisión de otros elementos en determinadas estructuras.

- Determinación del número y de la persona de los pronombres reflexivos.

- Concordancia en número y persona con el predicado. Considerada por los autores como propiedad morfosintáctica del sujeto, y no estrictamente sintáctica, la concordancia con el predicado es, en su opinión, la última propiedad conquistada por los semisujetos en un proceso que culmina con frecuencia en la sustitución de su forma originaria por la forma propia del sujeto. Los datos del griego, sin embargo, contradicen esta hipótesis: los semisujetos que muestran concordancia con el predicado no presentan necesariamente los demás comportamientos sintácticos propios del sujeto y, en ocasiones, tampoco sus propiedades semánticas y pragmáticas prototípicas ${ }^{31}$.

En las construcciones objeto de análisis estos tres fenómenos de orden general se manifiestan en diversos comportamientos sintácticos, descritos a continuación en detalle ${ }^{32}$. Estos comportamientos se ejemplifican con oracio-

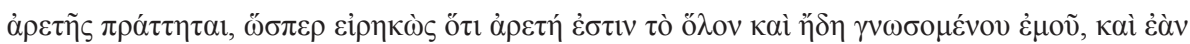

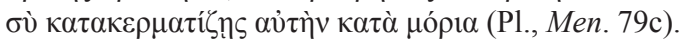

${ }^{30}$ Se trata, lógicamente, de complementos cuyas propiedades semánticas o pragmáticas son semejantes a las del sujeto prototípico. Sobre este punto, véase Sasse 1982, p. 272 ss.

${ }^{31}$ Este es el caso del genitivo que funciona como semisujeto en construcciones personales (cf. Conti 2008 [2010]) y, posiblemente, también el del genitivo semisujeto de las construcciones impersonales que aquí se analizan (cf. infra).

${ }^{32}$ El orden de presentación solo persigue una mayor claridad en la exposición y en la explicación de los fenómenos del griego. 
nes de sujeto prototípico y con oraciones del verbo gustar, cuyo complemento con referente humano y función de Experimentador parece, en principio, un buen candidato a semisujeto en español:

1. Posibilidad de elisión en oraciones coordinadas: «Me gustan las manzanas y las compro con frecuencia»/*Gustan las manzanas y las compro con frecuencia».

2. Posibilidad de que el predicado rija construcciones adverbiales de infinitivo cuyo sujeto, elidido, ha de ser correferencial con el sujeto del predicado regente ${ }^{33}$ : «No disfruto tanto con las manzanas como para comprarlas cada semana»/«No me gustan tanto las manzanas como para comprarlas cada semana».

3. Posibilidad de determinar el número y la persona de los pronombres reflexivos: «Luis es tan egocéntrico que solo se quiere a símismo»/«Luis es tan egocéntrico que solo se gusta a sí mismo».

4. Posibilidad de elisión en construcciones completivas de infinitivo cuando hay correferencialidad con el objeto del predicado regente ${ }^{34}$ : «Veo a Luis disfrutar con la ópera»/* «Veo a Luis gustar la ópera».

5. Posibilidad de elisión en construcciones completivas de infinitivo cuando hay correferencialidad con el sujeto del predicado regente: «Luis asegura disfrutar con la ópera»/* «Luis asegura gustar la ópera». Puesto que en griego antiguo el sujeto del infinitivo correferencial con el sujeto del predicado regente no siempre se elide, sino que en ocasiones se expresa mediante el acusativo, la sustitución del dativo analizado mediante el acusativo se habrá de considerar también un argumento a favor de su condición de semisujeto ${ }^{35}$.

6. Posibilidad de concordancia en número y persona con el predicado: «Luis adora las manzanas $\rangle / *^{*}$ A Luis le gusta las manzanas ${ }^{36}$. En algunas len-

${ }^{33}$ En referencia al infinitivo, empleo el término sujeto en el sentido laxo habitual en la tradición gramatical. Evidentemente, en las lenguas indoeuropeas antiguas el sujeto del infinitivo no presenta las propiedades morfosintácticas del sujeto de los predicados personales.

${ }^{34}$ Sobre las diferencias sintácticas existentes en griego entre las construcciones de infinitivo cuyo sujeto es correferencial con el objeto del predicado regente y aquellas otras cuyo sujeto no es correferencial con ningún complemento del predicado regente, véase Jiménez López 2003; para el latín, véase Bolkestein 1976.

${ }^{35}$ La expresión del sujeto del infinitivo en acusativo responde, en general, al deseo del hablante de subrayar la identidad de su referente o de contrastarla con la identidad de otros participantes. Sobre este punto, véanse, entre otros, Kühner y Gerth 1904, p. 30 s.

${ }^{36}$ En algunas variantes del español, tanto de España como de Hispanoamérica, el semisujeto de haber sí presenta concordancia con el predicado: Habían muchos niños jugando en la 
guas, la concordancia con el semisujeto se observa en oraciones impresivas; el referente del semisujeto, al que el hablante presupone control sobre el estado de cosas descrito, es el destinatario de la orden o de la prohibición $^{37}$ : «iLuis, disfruta de las manzanas!»/*«iLuis, gusta las manzanas!».

Si bien estos criterios han sido aceptados, en lo esencial, por otros autores que han abordado el problema de los semisujetos en lenguas indoeuropeas y no indoeuropeas ${ }^{38}$, en griego antiguo no todos los comportamientos atribuidos al sujeto en el mencionado trabajo son exclusivos de él y, por tanto, relevantes en la identificación de posibles semisujetos. Así, la elisión en oraciones coordinadas (17), el control de pronombres reflexivos (18) y el empleo de construcciones adverbiales de infinitivo con elisión del sujeto correferencial con el dativo (19) son comportamientos presentes en el dativo objeto de estudio, que, sin embargo, no demuestran su carácter de semisujeto. Se trata, en realidad, de comportamientos que, si bien caracterizan sobre todo al sujeto en griego antiguo, se observan también con cierta frecuencia en los restantes complementos inherentes del predicado ${ }^{39}$.

calle. En los demás puntos, el comportamiento del semisujeto de haber coincide con el comportamiento del de gustar.

${ }^{37}$ Cf. Haspelmath 2001, p. 70.

${ }^{38}$ Véanse, entre otros, el trabajo de Sasse 1982, que se ocupa de las lenguas indoeuropeas antiguas, los trabajos de Seefranz-Montag 1983 y 1984, centrados en un análisis diacrónico del inglés, el trabajo de Lazard 1998, que precisa las características morfosintácticas y designativas del sujeto en las lenguas de Europa, y el trabajo de Haspelmath 2001, que analiza, también en las lenguas de Europa, el concepto de sujeto y de semisujeto. Barðdal y Eythórsson, más críticos con las premisas de Cole y sus colegas, han analizado en diferentes trabajos las lenguas germánicas con criterios sincrónicos y diacrónicos (cf. Barðdal y Eythórsson 2003, Eythórsson y Barðdal 2005 y Barðdal 2006). Partiendo de los criterios establecidos por Lazard 1998, Baños 2003 analiza, desde una perspectiva sincrónica y diacrónica, las propiedades pragmáticas, semánticas y sintácticas del acusativo con referente humano de la construcción impersonal de paenitet; según demuestra el autor, el comportamiento del acusativo como semisujeto se consolida con el paso del tiempo y desemboca en la sustitución de la construcción impersonal por una personal.

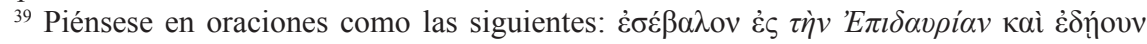
(Th. V 54.3) (elisión en oraciones coordinadas de uno de los elementos correferenciales con funciones sintácticas distintas); غ̇ं (empleo de construcciones adverbiales de infinitivo con elisión del sujeto correferencial con

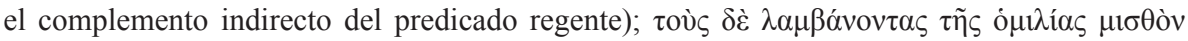
$\dot{\alpha} v \delta \rho \alpha \pi o \delta \imath \sigma \tau \grave{\alpha} \varsigma \dot{\varepsilon} \alpha v \tau \tilde{\omega} v \dot{\alpha} \pi \varepsilon \kappa \alpha ́ \lambda \varepsilon 1$ (X., Mem. I 2.6) (determinación por parte del complemento 


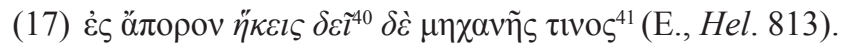

Has llegado a una situación desesperada y necesitas alguna artimaña

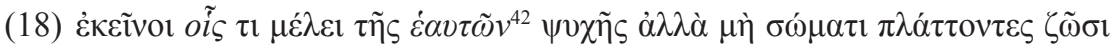
(P1., Phd. 82d)

Aquellos que se ocupan en algo de su propia alma y no viven para el cuerpo, modelándolo

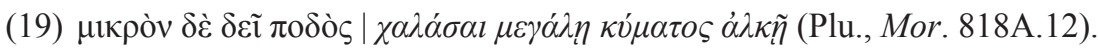

Apenas necesita de un pie la poderosa fuerza de una ola para calmarse.

Frente a los anteriores, los criterios de elisión en estructuras completivas de infinitivo y la concordancia en número y persona con el predicado sí son relevantes en griego antiguo en la definición del sujeto y de posibles semisujetos $^{43}$. En este sentido, el análisis del material seleccionado solo permite asegurar un comportamiento del dativo como semisujeto cuando se integra en estructuras completivas de infinitivo en las que es correferencial con el objeto del predicado regente.

En efecto, en estos contextos el dativo admite la elisión, tal y como muestra el siguiente pasaje, en el que el dativo de $\mu \varepsilon \tau \alpha \mu \varepsilon ́ \lambda \varepsilon \imath$, correferencial con el acusativo de la construcción causativa de غ̇ंđoíc1, no se expresa. Obsérvese que

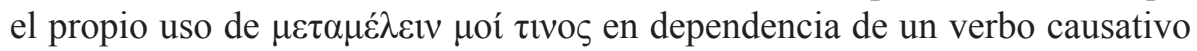
presupone la atribución al Experimentador de un cierto grado de control sobre la acción verbal ${ }^{44}$ :

directo del número y de la persona de los pronombres reflexivos). Sobre estos criterios sintácticos en griego, véase Conti 2009 [2010], pp. 193-196.

${ }^{40}$ Puesto que con $\delta \varepsilon \tilde{~}$ el Experimentador se expresa mediante el dativo y mediante el acusativo, en ejemplos como este no podemos descartar que nos hallemos ante la elisión de este último.

${ }^{41}$ Frente a ejemplos como este, en la mayoría se elide el sujeto de una de las oraciones co-

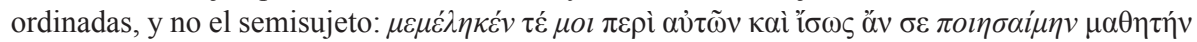
(Pl., Cra. 428.b).

${ }^{42}$ Los pronombres reflexivos alternan en estos contextos con pronombres anafóricos no reflexivos, como en (21). Sobre el uso de los pronombres reflexivos en griego véanse los trabajos de Powell 1933 y 1934; para una visión global de los pronombres en griego cf. Méndez Dosuna 2007.

${ }^{43}$ Cf. Conti 2009 [2010], pp. 196-198.

${ }^{44}$ La construcción personal con codificación del Experimentador en dativo también se

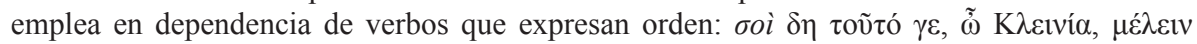
$\pi \alpha \rho \alpha \kappa \varepsilon \lambda \varepsilon v ́ о \mu \alpha l$ (P1., Lg. 969a). 


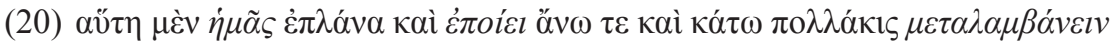

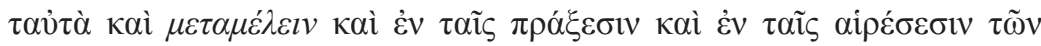

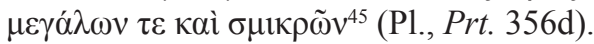

Esta (sc. la fuerza de las apariencias) nos desviaba y nos hacía cambiar muchas veces las mismas cosas hacia arriba y hacia abajo y arrepentirnos sobre lo grande y sobre lo pequeño en nuestros actos y en nuestras elecciones.

Por el contrario, cuando se emplea en estructuras completivas de infinitivo en las que es correferencial con el sujeto del predicado regente, el comportamiento del dativo se aleja del comportamiento del sujeto prototípico. Tal y como muestra el ejemplo siguiente, el dativo, correferencial con el sujeto del predicado regente, ni se elide ni se sustituye mediante el acusativo ${ }^{46}$. La construcción impersonal se mantiene sin cambios:

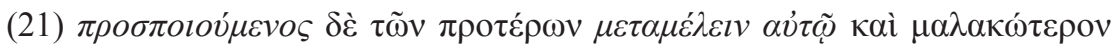

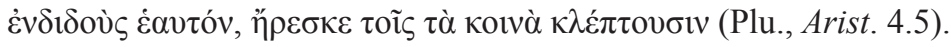

Fingiendo arrepentirse de sus acciones pasadas y mostrándose más blando, complacía a quienes robaban el erario público.

El comportamiento del dativo podría indicar que en las estructuras completivas de infinitivo la conquista de la elisión en caso de correferencialidad con el sujeto del predicado regente es fruto de un proceso más largo que el de la conquista de la elisión en caso de correferencialidad con el objeto. Se trata, sin embargo, de una mera hipótesis cuya demostración exigiría el análisis del comportamiento de otros semisujetos, tanto en griego como en otras lenguas indoeuropeas ${ }^{47}$. De momento, la cuestión queda, pues, abierta.

${ }^{45}$ Ha de excluirse una posible construcción personal de $\mu \varepsilon \tau \alpha \mu \varepsilon \dot{\lambda} \omega$, pues cuando el sujeto designa un ser humano con función de Experimentador el verbo presenta formas medias: oi

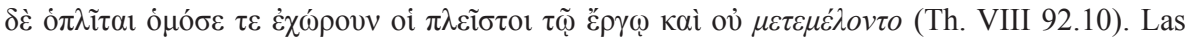
construcciones personales en las que el verbo se emplea en voz activa se corresponden, por lo general, con una codificación del Experimentador como segundo complemento en dativo;

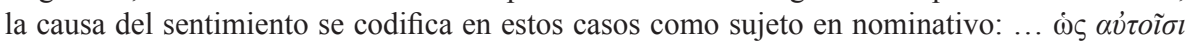

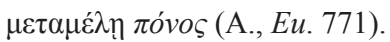

${ }^{46}$ Obviamente, el hecho de que un fenómeno no se observe en los autores seleccionados no significa que sea agramatical en griego antiguo.

${ }^{47}$ Si la elisión en caso de correferencialidad con el objeto del predicado regente exige del semisujeto menos proximidad semántica y funcional al sujeto que la elisión en caso de correferencialidad con el sujeto, cabría esperar que los semisujetos que no admitan la elisión cuando 
La concordancia del dativo con el predicado en número y persona tampoco se documenta en los autores seleccionados. De hecho, aunque se observa el uso impresivo de las construcciones impersonales de los verbos que expresan interés, dicho uso no está vinculado, como en otras lenguas, con el reanálisis del Experimentador como semisujeto sintáctico (cf. supra). Tal y como muestra el siguiente pasaje, el verbo se emplea en tercera persona del singular, y no en concordancia con el dativo:

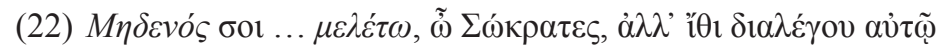
(Pl., Ly. 211c).

Que nada te preocupe, Sócrates, sino ve y habla con él.

El empleo mismo de las construcciones objeto de análisis en la expresión de órdenes y de prohibiciones es ya relevante, pues los verbos impersonales excluyen cualquier sujeto sintáctico referencial y, por consiguiente, todo posible destinatario de un mensaje impresivo ${ }^{48}$. No es un hecho sorprendente, por tanto, que el uso impresivo de las construcciones impersonales con uno o más participantes desencadene en algunas lenguas un reanálisis semántico y sintáctico que convierta a alguno de estos participantes en destinatario del mensaje y, en consecuencia, en semisujeto sintáctico portador de la concordancia con el predicado. En el caso del material seleccionado para este trabajo, solo el genitivo admite una interpretación como semisujeto sintáctico ${ }^{49}$. En efecto, en oraciones como la de (22) solo puede plantearse una posible concordancia

son correferenciales con el objeto del predicado regente tampoco la admitan cuando lo son con el sujeto. Este es el caso, por ejemplo, del genitivo de las construcciones impersonales objeto de estudio (cf. § II 2). Sobre el acusativo de la construcción me paenitet alicuius, que admite la elisión cuando es correferencial con el sujeto del predicado regente y también cuando lo es con el objeto, cf. Baños 2003, p. 65 ss.

${ }^{48}$ En las lenguas indoeuropeas el empleo de oraciones impersonales en mensajes impresivos es un fenómeno muy restringido condicionado con frecuencia por factores contextuales. Piénsese, por ejemplo, en oraciones del español como ;Que refresque! o QQue te baste con eso! En los autores analizados, los verbos que designan fenómenos meteorológicos solo documentan

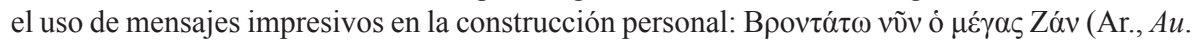
570). Téngase en cuenta que en los mensajes impresivos prototípicos el hablante presupone tanto su control sobre el Agente como el control de este Agente sobre la acción verbal (cf. Crespo 1997, p. 57 s.).

${ }^{49}$ Compárese la oración de (22) con oraciones en las que el Experimentador se codifica también en dativo, pero el sujeto sintáctico presenta su codificación habitual en nominativo: $\sigma o \grave{i}$

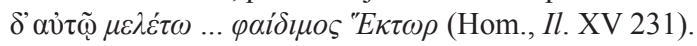


en número y persona entre el predicado y el genitivo, concordancia documentada, por lo demás, con otros verbos y en otros contextos (cf. § I). Con todo, también cabe suponer que el empleo en mensajes impresivos no haya desencadenado en griego un reanálisis de las construcciones impersonales en construcciones personales, pues no parece haber ejemplos en los que tanto el genitivo como el predicado se empleen en plural.

Vemos, pues, cómo el dativo objeto de estudio presenta todos los comportamientos sintácticos característicos del sujeto en griego antiguo, aunque no exclusivos de él, pero tan solo una parte de los que sí parecen definir al sujeto frente a los demás complementos del predicado.

Junto a los criterios propuestos por Cole y sus colegas, el material seleccionado ofrece ejemplos de un fenómeno que apoya la interpretación del dativo como semisujeto. Se trata del empleo en anacoluto del nominativo en lugar del dativo. Este uso del llamado nominativo pendens refleja la proximidad entre el complemento codificado en dativo y el sujeto de la oración ${ }^{50}$. Las propiedades denotativas y semánticas del dativo facilitan su identificación con el sujeto y con su codificación gramatical, aunque no desencadenan la concordancia en número y persona con el predicado, característica del sujeto:

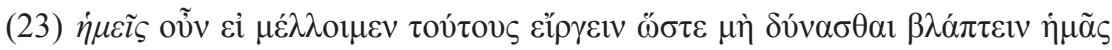

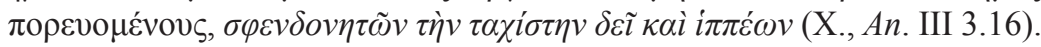

Pues nosotros, si queremos impedir que puedan atacarnos en nuestro avance, nos hacen falta cuanto antes honderos y jinetes.

\section{Contraste entre las propiedades sintácticas del dativo y las del genitivo}

Además de la concordancia en número y persona con el predicado, excluida en el caso del dativo, pero no en el del genitivo, hay otras diferencias entre las propiedades sintácticas del dativo y las del genitivo en las construcciones analizadas $^{51}$. Así, el uso en aposición o en coordinación con una estructura

\footnotetext{
${ }^{50}$ Piénsese en oraciones del español del tipo Yo me gustan las manzanas si están bien maduras, propias del habla coloquial. Al nominativo pendens se le atribuye en general la función pragmática de tema (cf., entre otros, Adrados 1992, p. 77 s.); los elementos con esta función, situados fuera de la cláusula, proporcionan al oyente unas coordenadas que dan sentido a la información que se transmite en la propia cláusula (cf. Dik 1978, p. 13).

${ }^{51}$ Sobre las propiedades del genitivo, cf. Conti 2009 [2010].
} 
completiva de sujeto, fenómeno frecuente en el genitivo (cf. § I), no se observa en el dativo. La divergencia entre las propiedades designativas y semánticas de las estructuras completivas y las del dativo objeto de estudio explican este hecho. Así, mientras que las estructuras completivas no designan entidades, sino tan solo situaciones y, con menor frecuencia, propiedades ${ }^{52}$, el dativo designa por regla general entidades concretas de carácter humano. Por otra parte, las funciones semánticas expresadas por las estructuras completivas están muy alejadas de la función de Experimentador propia del dativo en estos contextos, pero no de las funciones del genitivo ${ }^{53}$. Las propiedades sintácticas del dativo que hacen de él un semisujeto son, pues, insuficientes para permitir la aposición o la coordinación con estructuras completivas en función de sujeto: la identidad - o proximidad - entre estructuras coordinadas ha de ser no solo sintáctica y pragmática, sino también designativa y semántica ${ }^{54}$.

Otras propiedades sintácticas características del sujeto solo se observan, por el contrario, en el dativo, pero no en el genitivo. Este es el caso de la determinación del número y de la persona de los pronombres reflexivos - fenómeno que, como hemos visto, en griego no es exclusivo del sujeto- y de la elisión en construcciones completivas de infinitivo en caso de correferencialidad con el objeto del predicado regente. El hecho de que la determinación de la persona y del número de los pronombres reflexivos sea una propiedad del dativo responde, en mi opinión, al estrecho vínculo de la anáfora reflexiva con entidades humanas que tienen control, aunque solo sea en cierto grado, sobre la acción verbal ${ }^{55}$. Más difícil resulta explicar el contraste entre la falta de ejemplos de la elisión del genitivo en construcciones completivas de infinitivo cuando es correferencial con el objeto del predicado regente y la presencia de ejemplos en el caso del dativo. Posiblemente, la asociación frecuente del genitivo en estos contextos

${ }^{52}$ Las completivas designan, por lo general, situaciones, aunque en su uso como predicado de oraciones copulativas admiten un análisis como designación de una propiedad (cf., entre otros, Crespo 1999, p. 54 s., y Conti 2007, pp. 3, 13). El genitivo de las construcciones analizadas designa con cierta frecuencia situaciones.

${ }^{53}$ Como es sabido, las completivas expresan, además de la llamada función cero, propia del sujeto de predicados copulativos (Dik 1997, p. 15), las funciones de Resultado, Paciente y Causa-Fin (cf., entre otros, Crespo 1999, pp. 51-53, y Conti 2007, pp. 11-12).

${ }^{54}$ Véase, entre otros, Dik 1997, p. 189 ss.

${ }^{55}$ Cf. Kemmer 1993, p. 42 ss. 
con la designación de entidades no humanas a las que es difícil atribuir control sobre el estado de cosas descrito sea un factor decisivo en este punto.

La aplicación de los criterios de Cole y sus colegas a las construcciones impersonales objeto de estudio permite, pues, concluir que el comportamiento sintáctico del dativo se aproxima más al del sujeto prototípico que el del genitivo. Ahora bien, si nos ceñimos a los comportamientos que parecen definir en griego antiguo al sujeto frente al resto de los complementos inherentes del predicado, el equilibrio entre el dativo y el genitivo resulta innegable: ni el genitivo ni el dativo ofrecen ejemplos de elisión en construcciones completivas de infinitivo en las que son correferenciales con el sujeto del predicado regente; la elisión en construcciones completivas de infinitivo cuando hay correferencialidad con el objeto del predicado regente, por su parte, solo se observa en el dativo, pero no en el genitivo; por último, la concordancia con el predicado verbal, con el correspondiente reanálisis de la construcción impersonal en una construcción personal, solo cabe suponerla en el caso del genitivo, pero no en el del dativo. Nos hallamos, por tanto, ante dos semisujetos cuyo comportamiento sintáctico, sin identidad con el del sujeto prototípico, está condicionado por sus respectivas propiedades designativas y semánticas. Así, el genitivo, que admite sin dificultad una interpretación como delimitador del espectro semántico del predicado verbal, admite también un reanálisis como el constituyente sintáctico más relevante del predicado. Este reanálisis sintáctico propicia, en estos y en otros contextos, la concordancia en número y persona del genitivo con el predicado y es, probablemente, un factor importante en la posibilidad de aposición y de coordinación con estructuras completivas. Frente a ello, el dativo presenta los comportamientos sintácticos más estrechamente vinculados con la designación de seres humanos y con el control; este es el caso de la determinación del número y de la persona de los pronombres reflexivos y tal vez también de la posibilidad de elisión en construcciones completivas de infinitivo cuando el dativo es correferencial con el objeto del predicado regente. A su vez, el hecho de que en la designación de seres humanos el nominativo sustituya ocasionalmente al dativo, pero sin concordancia con el predicado verbal, refleja una proximidad entre el dativo y el nominativo no tanto sintáctica como designativa, semántica y pragmática.

La relación siguiente refleja las diferencias y las similitudes sintácticas observadas entre el dativo y el genitivo en las construcciones objeto de análisis. Las diferencias están marcadas en cursiva: 
1. Elisión en oraciones coordinadas: Dativo: $+/ /$ Genitivo $^{56}:+$

2. Rección de construcciones adverbiales de infinitivo con elisión del sujeto correferencial con el semisujeto del predicado regente: Dativo: + // Geni$\operatorname{tivo}^{57}:+$

3. Determinación del número y de la persona de pronombres reflexivos: $D a$ tivo: + // Genitivo: -

4. Elisión en construcciones completivas de infinitivo cuando hay correferencialidad con el objeto del predicado regente: Dativo: + // Genitivo: -

5. Elisión en construcciones completivas de infinitivo cuando hay correferencialidad con el sujeto del predicado regente: Dativo: - // Genitivo: -

6. Concordancia en número y persona con el predicado en oraciones impresivas: Dativo: - // Genitivo: +?

7. Uso en aposición o en coordinación con estructuras completivas de sujeto: Dativo: - // Genitivo: +

\section{Conclusiones}

1. A pesar de su carácter heredado, las construcciones impersonales con un complemento en genitivo y otro en dativo son en griego antiguo un fenómeno posthomérico limitado a un número muy reducido de lexemas verbales

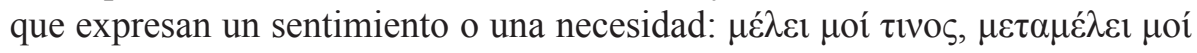

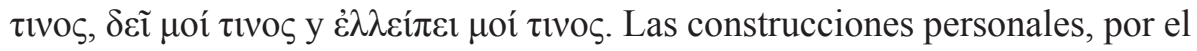
contrario, se documentan ya desde Homero en la descripción de un sentimiento, una necesidad o una sensación; se trata de dos tipos de oraciones: en uno, el sujeto codificado en nominativo se corresponde con el complemento en dativo de la construcción impersonal; en otro, con el complemento en genitivo.

2. En las construcciones impersonales objeto de estudio, el dativo presenta unas características designativas, semánticas y pragmáticas muy próximas a las del sujeto prototípico: su referente es humano, su función semántica es la de Experimentador y su función pragmática más frecuente parece ser la de tópico.

${ }^{56}$ La posibilidad de elidir en dos oraciones coordinadas el semisujeto en genitivo o el sujeto

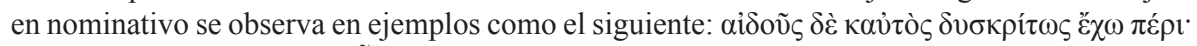

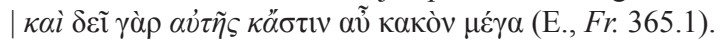

${ }^{57}$ Pasajes como el siguiente muestran la elisión del sujeto de un infinitivo final cuando es correferencial con el genitivo semisujeto del predicado regente: $\delta \grave{\eta} \delta \varepsilon \tilde{\imath} \varphi \rho \alpha \dot{\alpha} \delta o v o \varsigma \alpha \dot{\alpha} v \delta \rho \grave{\varsigma} \varsigma$

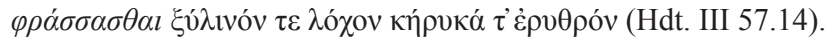


3. En griego antiguo, las peculiaridades sintácticas del sujeto frente al resto de los complementos inherentes del predicado son menos que en las lenguas analizadas por Cole y sus colegas en su intento de definir el sujeto: solo los fenómenos relacionados con la elisión en construcciones completivas de infinitivo y la concordancia en número y persona con el predicado parecen ser en griego antiguo exclusivos del sujeto. Esta posición sintáctica poco marcada es un rasgo característico del sujeto no solo en griego, sino también en otras lenguas indoeuropeas antiguas; paulatinamente, el sujeto se aleja del resto de los complementos y se consolida como el constituyente más importante en la jerarquía sintáctica.

4. En las construcciones impersonales objeto de estudio, tanto el dativo como el genitivo admiten un análisis como semisujeto. El dativo presenta dos rasgos característicos del sujeto prototípico: la designación de seres humanos y el control sobre la acción verbal, al menos en un cierto grado. Son las propiedades sintácticas del sujeto vinculadas con estos dos rasgos las que están también presentes en el dativo. El genitivo, por el contrario, se caracteriza por unas propiedades presentes también en el sujeto, pero no en el sujeto prototípico: la designación de entidades tanto animadas como inanimadas y la expresión del Paciente y de la Causa. Estas propiedades del genitivo permiten la aposición y la coordinación con estructuras completivas de sujeto. Por otra parte, el valor partitivo del genitivo favorece una interpretación del caso como delimitador del espectro semántico del predicado verbal, lo que a su vez propicia su reanálisis como el constituyente sintáctico más relevante del predicado. La concordancia en número y persona con el predicado, propia del genitivo semisujeto en otros contextos y tal vez también en los contextos objeto de estudio, es el reflejo morfosintáctico de estos procesos.

5. Tal y como demuestra el material analizado, en griego antiguo la concordancia con el predicado no es necesariamente el resultado final de un proceso de aproximación sintáctica al sujeto que desemboca en la sustitución de la forma originaria del semisujeto por el nominativo. En griego antiguo, un semisujeto que presente concordancia con el predicado no ha de presentar necesariamente todas las demás propiedades sintácticas del sujeto. Por lo demás, las construcciones personales con un sujeto en nominativo conviven en la lengua con construcciones personales e impersonales con un semisujeto, y no siempre son más recientes que estas. 


\section{BIBLIOGRAFÍA}

Adrados, F. R. 1992: Nueva sintaxis del griego antiguo, Madrid.

Baños, J. M. 2003: «Paenitet y los verbos impersonales de sentimiento en latín: sintaxis y pragmática del acusativo personal», en Baños, Cabrillana, Torrego y Villa (eds.), pp. 51-77.

Baños, J. M., Cabrillana Leal, C., Torrego Salcedo, M. E. y Villa Polo, J. de la (eds.) 2003: Praedicatiua. Complementación en griego y latín, Verba Anexo 53, Santiago de Compostela

Barðdal, J. 2006: «Construction-specific properties of syntactic subjects in Icelandic and German», Cognitive Linguistics 17, 1, pp. 39-106.

Barðdal, J. y Eythórsson, T. 2003: «The change that never happened: The story of the oblique subjects», Journal of Linguistics 39, 3, pp. 439-472.

Bello, A. 1847: Gramática de la lengua castellana, edición crítica de R. Trujillo, Santa Cruz de Tenerife, 1981.

Bhaskararao, P. y Karumuri Venkata, S. (eds.) 2004: Non-Nominative Subjects, Ámsterdam.

Bolkestein, M. 1976: «A.c.i- and ut-clauses with verba dicendi in Latin», Glotta 54, pp. 263-291.

Bossong, G. 1998: «Le marquage de l'expièrent dans les langues d'Europe», en Feuillet (ed.), pp. 259-294.

Brugmann, K. 1925: Die Syntax des einfachen Satzes im Indogermanischen, BerlínLeipzig.

Chafe, W. L. 1976: «Givenness, contrastiveness, definiteness, subjects, topics, and points of view», en Li (ed.), pp. 25-55.

Cole, P., Harbert, W., Hermon, G. y Sridhar, S. N. 1980: «The acquisition of subjecthood», Language 56, 4, pp. 719-743.

Conti, L. 2007: Las completivas en griego antiguo, ISBN 84-9822-570-1, 〈http:// www.liceus.com/bonos/compra1.asp?idproducto=1062> (08/07/2010).

— 2008 [2010]: «Synchronie und Diachronie des altgriechischen Genitivs als Semisubjekt», HS 121, pp. 94-113.

— 2009 [2010]: «Weiteres zum Genitiv als Semisubjekt im Altgriechischen: Analyse des Kasus bei impersonalen Konstruktionen», HS 122, pp. 182-207.

Crespo, E. 1983: «Sobre el orden de palabras en griego: de SOV hacia SVO», en Unidad y pluralidad en el mundo antiguo. Actas del VI Congreso Español de Estudios Clásicos II, Madrid, pp. 287-294.

- 1997: «Delbrück y la sintaxis de los modos», en Crespo, E. y García Ramón, J. L. (eds.), Berthold Delbrück y la sintaxis indoeuropea hoy. Actas del coloquio de la Indogermanische Gesellschaft, Madrid-Wiesbaden, pp. 27-62. 
Crespo, E. 1999: «Paramètres pour la définition des complétives en grec ancien», en Jacquinod (ed.), pp. 45-62.

Crespo, E., Conti, L. y Maquieira, H. 2003: Sintaxis del griego clásico, Madrid.

Cuzzolin, P. 2007: «Impersonali e semantica dei predicati in greco antico», en Cuzzolin, P. y Napoli, M. (eds.), Fonologia e tipologia lessicale nella storia della lingua greca, Milán, pp. 70-85.

Cuzzolin, P. y Napoli, M. 2009: «An Overview of the Impersonals in Proto-IndoEuropean», en Lühr, R. y Ziegler, S. (eds.), Protolanguage and Prehistory. Akten der XII Fachtagung der Indogermanischen Gesellschaft in Krakau, Wiesbaden, pp. 75-81.

Delbrück, B. 1968²: Altindische Syntax, Darmstadt.

Dik, H. 1995: Word Order in Ancient Greek. A Pragmatic Account of Word Order Variation in Herodotus, Ámsterdam.

- 2007: Word Order in Greek Tragic Dialogue, Oxford.

Dik, S. C. 1978: Functional Grammar, Dordrecht.

- 1997: The Theory of Functional Grammar, Part 2, Complex and Derived Constructions (ed. K. Hengeveld), Berlín.

Dover, K. J. 1960: Greek Word Order, Cambridge.

Eythórsson, T y Barðdal, J. 2005: «Oblique subjects: A common Germanic inheritance», Language 81, 4, pp. 824-881.

Feuillet, J. (ed.) 1998: Actance et Valence dans les Langues de l'Europe, BerlínNueva York.

Fillmore, Ch. 1968: «Case for case», en Harms, R. Th. (ed.), Universals in linguistic theory, Nueva York, pp. 1-88.

Frisk, H. 1932: Studien zur griechischen Wortstellung, Gotemburgo.

García Ramón, J. L. 1999: «Les complétives infinitives avec $̋ \sigma \tau \varepsilon$, en Jacquinod (ed.), pp. 167-190.

Hartmann, H. 1977: «Das Impersonale im Keltischen und Indogermanischen. Probleme der Dominanz», en Ködderitzsch, R. y Schmidt, K. H. (eds.), Indogermanisch und Keltisch. Kolloquium der Indogermanischen Gesellschaft am 16. und 17. Februar 1976 in Bonn, Wiesbaden, pp. 159-203.

Haspelmath, M. 2001: «Non-canonical marking of core arguments in European languages», en Aikhenvald, A. Y., Dixon, R. M. W. y Onishi, M. (eds.), Non canonical Marking of Subjects and Objects, Ámsterdam, pp. 53-81.

Hermann, E. 1926: «Die subjektlosen Sätze bei Homer und der Ausdruck der Tätigkeit, des Vorgangs und des Zustands», Nachrichten von der Gesellschaft der Wissenschaften zu Göttingen. Philologisch-Historische Klasse, Heft 3.

Hettrich, H. 2007: Materialien zu einer Kasussyntax des Rgveda, Universität Würzburg, Institut für Altertumswissenschaften, Lehrstuhl für Vergleichende Sprach- 
wissenschaft 〈http://www.vergl-sprachwissenschaft.phill.uni-wuerzburg.de/materialien/Materialien\%20-\%20Lokativ+Dativ.pdf> (08/07/2010).

Itagaki, N. y Prideaux, D. 1985: «Nominal properties as determinants of subject selection», Lingua 66, pp. 135-149.

Jacquinod, B. (ed.) 1999: Les complétives en grec ancien, Saint-Étienne.

Jiménez López, M. D. 2003: «Estructuras sintácticas de los verbos de influencia», en Baños, Cabrillana, Torrego y Villa (eds.), pp. 111-137.

Keenan, E. 1976: «Towards a universal definition of 'subject'», en Li (ed.), pp. 303-334.

Keenan, E. y Comrie, B. 1977: «Noun phrase accessibility and universal grammar», Linguistic Inquiry 8, pp. 63-99.

Kemmer, S. 1993: The Middle Voice, Ámsterdam.

Krahe, H. 1972: Grundzüge der Vergleichenden Syntax, Innsbruck.

Kühner, R. y Gerth, B. 1904: Ausführliche Grammatik der griechischen Sprache, II.2, Hanóver.

Lazard, G. 1998: «Définition des actants dans les langues européennes», en Feuillet (ed.), pp. 11-146.

Li, Ch. N. (ed.) 1976: Subject and Topic, Nueva York.

Li, Ch. N. y Thompson, S. 1976: «Subject and topic: A new typology of language», en Li (ed.), pp. 457-490.

Meillet, A. $1937^{8}$ : Introduction à l'étude comparative des langues indoeuropéennes, París.

Méndez Dosuna, J. 2007: Los pronombres en griego antiguo, ISBN 84-9822-017-3 〈http://www.liceus.com/bonos/compra1.asp?idproducto=495〉 (08/07/2010).

Miklosich, F. 1883: Subjectlose Sätze, Viena.

Moreno, J. C. 1990a: «Universal and typological aspects of impersonality», en Bahner, W., Schildt, J. y Viehweger, D. (eds.), Proceedings of the Fourteenth International Congress of Linguists, III, Berlín, pp. 2396-2398.

- 1990b: «Processes and actions: internal agentless impersonals in some European languages», en Bechert, J., Bernini, G. y Buridant, C. (eds.), Toward a Typology of European Languages, Berlín-Nueva York, pp. 255-272.

Powell, J. E. 1933: «Studies on the Greek Reflexive: Herodotus», CQ27, pp. 208-221.

- 1934: «Studies on the Greek Reflexive: Thucydides», CQ 28, pp. 159-174.

Sasse, H.-J. 1982: «Subjektprominenz», en Heinz, S. y Wandruszka, U. (eds.), Fakten und Theorien. Festschrift für Helmut Stimm zum 65. Geburtstag, Tubinga, pp. 266-286.

Schwyzer, E. y Debrunner, A. 19885: Griechische Grammatik II 1.2., Múnich.

Seefranz-Montag, A. von 1983: Syntaktische Funktionen und Wortstellungsveränderung. Die Entwicklung «subjektloser» Konstruktionen in einigen Sprachen, Múnich.

- 1984: «Subjectless Constructions and Syntactic Change», en Fisiak, J. (ed.), Historical Syntax, Berlín, pp. 521-553. 
Wackernagel, J. 1920: Vorlesungen über Syntax I, Gotinga.

Wegener, H. 2001: «Verbs of affect from a synchronic and diachronic perspective», en Dehé, N. y Wanner, A. (eds.), Structural aspects of semantically complex verbs, Fráncfort, pp. 219-248.

Fecha de recepción de la primera versión del artículo: 23/11/2009

Fecha de recepción de la versión definitiva del artículo: 01/07/2010

Fecha de aceptación del artículo: 12/05/2010 